\title{
Pulmonary Therapy 2020 Update and Podcast: Meet the Journal's Editors-in-Chief
}

Kai-Michael Beeh · Rajiv Dhand

Received: March 6, 2020 / Published online: April 9, 2020

(C) The Author(s) 2020

\section{ABSTRACT}

The Editors-in-Chief of Pulmonary Therapy have prepared podcasts summarizing their current research, recent highlights from the field, and future predictions. Audio-only versions and the transcripts can be downloaded here: https:// doi.org/10.6084/m9.figshare.11938863. Following this is a written summary of the journal's recent developments and the transcripts from the podcasts.

Kai-Michael Beeh and Rajiv Dhand are first authors.

Enhanced Digital Features To view digital features for this article go to https://doi.org/10.6084/m9.figshare. 11938863

Electronic supplementary material The online version of this article (https://doi.org/10.1007/s41030020-00114-9) contains supplementary material, which is available to authorized users.

K.-M. Beeh ( $\square)$

INSAF Respiratory Research Institute, Wiesbaden, Germany

e-mail: k.beeh@insaf-wi.de

R. Dhand

Department of Medicine, Graduate School of Medicine, University of Tennessee Medical Center, Knoxville, TN, USA

e-mail: rdhand@utmck.edu
Keywords: Asthma; COPD; Coronavirus; Podcast; Pulmonary medicine; Respiratory

\section{EDITORIAL}

Dear Readers,

Last year, we published an Editorial [1] in which we reflected on Pulmonary Therapy's development, and the field of pulmonary research in general. We would, again, like to reflect on this, as there have been a number of new developments.

First and foremost, we would like to formally welcome Professor Rajiv Dhand, from the University of Tennessee Graduate School of Medicine, as our new US-based Editor-in-Chief. Professor Dhand joins Dr. Kai-Michael Beeh, our current Europe-based Editor-in-Chief. A full list of our current board members can be found here: https://www.springer.com/journal/41030/ editors.

We are pleased to announce that the journal is now indexed on PubMed, and all content published in the December 2017 issue and onwards has been retrospectively indexed on the site here: https://www.ncbi.nlm.nih.gov/ pmc/journals/3773/.

As you will notice above, in the online version of this Editorial below the abstract, Pulmonary Therapy now has the capacity to host videos and podcasts embedded within the article itself. Our two Editors-in-Chief have 
recorded a podcast highlighting their current research, advances in their area over the past year, and future directions. You can also download the audio-only version on the article's Figshare page, alongside the transcripts: https://doi.org/10.6084/m9.figshare.11938863.

The journal is also able to host a number of other 'digital features' including videos, animations, slide decks, and more. These are designed to increase visibility, readership, and the educational value of the content.

Pulmonary Therapy launched a "Patient and Physician Perspectives" series late in 2018 and we have continued to receive submissions throughout 2019. These commentaries are designed to give patients a voice in scientific publications. Typically, the first half of the article is authored by a patient, describing their experience of living with their particular condition, the second half is authored by a physician and healthcare professional who draws on the patient's experience in light of the published literature. A number of articles are planned for 2020, and you can read them all here: https://link.springer.com/journal/ 41030/topicalCollection/AC_450cc146be7a92bfec 5f45e7ab9e7737.

We must thank all of our contributors who are pivotal to the journal's continued progress. Our Editorial and Advisory board members are vital in assisting the in-house editorial team with peer-review decisions and journal development. We also thank our authors and contributors who provide the content and trust in the journal's rapid, high-quality peer review, editorial policies and open access. Lastly, we'd like to thank our readers, who we hope find educational and scientific value in our content. We strive to publish scientifically robust, freely available educational content that can assist healthcare professionals and researchers to, ultimately, treat patients in this area. In recognition of this, Table 1 highlights five of our most highly read articles in 2019.

Finally, we invite our readers to consider submitting their work to Pulmonary Therapy. As discussed in the video podcasts, there are a number of developments in the field, on which we look forward to publishing in 2020.

Kai-Michael Beeh, EU Editor-in-Chief

Rajiv Dhand, US Editor-in-Chief
Table 1 Pulmonary Therapy's five most highly read articles in 2019

\begin{tabular}{|c|c|c|}
\hline Article & Link & Description \\
\hline $\begin{array}{l}\text { Inhaler Devices for } \\
\text { Delivery of } \\
\text { LABA/LAMA } \\
\text { Fixed-Dose } \\
\text { Combinations in } \\
\text { Patients with } \\
\text { COPD }\end{array}$ & $\begin{array}{l}\text { https://doi. } \\
\text { org/10. } \\
\text { 1007/ } \\
\text { s41030-019- } \\
\text { 0090-1 }\end{array}$ & $\begin{array}{l}\text { A review article } \\
\text { with over } 1800 \\
\text { downloads to } \\
\text { date }\end{array}$ \\
\hline $\begin{array}{l}\text { Chronic Cough in } \\
\text { Adults: Make the } \\
\text { Diagnosis and } \\
\text { Make a } \\
\text { Difference }\end{array}$ & $\begin{array}{l}\text { https://doi. } \\
\text { org/10. } \\
\text { 1007/ } \\
\text { s41030-019- } \\
0089-7\end{array}$ & $\begin{array}{l}\text { A review article } \\
\text { providing } \\
\text { practical } \\
\text { diagnosis } \\
\text { management } \\
\text { strategies with } \\
\text { over } 1700 \\
\text { downloads to } \\
\text { date }\end{array}$ \\
\hline $\begin{array}{l}\text { Epidemiology of } \\
\text { Pulmonary } \\
\text { Fibrosis: A } \\
\text { Cohort Study } \\
\text { Using Healthcare } \\
\text { Data in Sweden }\end{array}$ & $\begin{array}{l}\text { https://doi. } \\
\text { org/10. } \\
\text { 1007/ } \\
\text { s41030-019- } \\
0087-9\end{array}$ & $\begin{array}{l}\text { An original } \\
\text { research article } \\
\text { with over } 1600 \\
\text { downloads to } \\
\text { date }\end{array}$ \\
\hline $\begin{array}{l}\text { Asthma Diagnosis: } \\
\text { The Changing } \\
\text { Face of } \\
\text { Guidelines }\end{array}$ & $\begin{array}{l}\text { https://doi. } \\
\text { org/10. } \\
\text { 1007/ } \\
\text { s41030-019- } \\
\text { 0093-y }\end{array}$ & $\begin{array}{l}\text { A review article } \\
\text { highlighting the } \\
\text { history and } \\
\text { evidence behind } \\
\text { published } \\
\text { guidelines with } \\
\text { over } 1100 \\
\text { downloads }\end{array}$ \\
\hline $\begin{array}{l}\text { In Vitro Study of } \\
\text { the Effect of } \\
\text { Breathing } \\
\text { Pattern on } \\
\text { Aerosol Delivery } \\
\text { During High- } \\
\text { Flow Nasal } \\
\text { Therapy }\end{array}$ & $\begin{array}{l}\text { https://doi. } \\
\text { org/10. } \\
\text { 1007/ } \\
\text { s41030-019- } \\
\text { 0086-x }\end{array}$ & $\begin{array}{l}\text { An original } \\
\text { research article } \\
\text { with over } 800 \\
\text { downloads }\end{array}$ \\
\hline
\end{tabular}




\section{PODCAST TRANSCRIPTS}

\section{Meet the Journal's Editor-in-Chief Dr. Kai- Michael Beeh}

CV: Hello and thank you for listening to the first Pulmonary Therapy podcast, which has been created alongside our 2020 editorial update. My name is Christopher Vautrinot and I am the managing editor of the journal. We thought, considering this is the first podcast, it was an excellent opportunity to introduce the journal's Editors-in-Chief, Dr. Kai-Michael Beeh, and Professor Rajiv Dhand. They will discuss their ongoing research focus and comment on the current and future direction of pulmonary medicine.

CV: I'm joined by Dr. Kai-Michael Beeh, the founder and director of INSAF respiratory research institute in Wiesbaden Germany. Dr. Beeh is the EU-based Editor-in-Chief for Pulmonary Therapy and joined the journal at its launch in 2015. Dr. Beeh is an internationally recognized researcher in the area of pathophysiology and pharmacotherapy of chronic airway diseases.

CV: So Dr. Beeh, could you describe in more detail your area of expertise and current research focus?

KB: Well thank you Chris, happy to join you for this podcast. So my role and my area of expertise is that I'm a pulmonologist by training and, as the medical director of the INSAF respiratory research institute in Wiesbaden, Germany, my main focus is to develop new treatments or look for new treatments in the field of airway diseases; mainly asthma and COPD. So currently we are undertaking a lot of mechanistic and early phase studies looking into asthma, for example, at both ends of the spectrum in severe asthma as an add-on therapeutic approach, but also in milder forms of asthma replacements of alternatives for inhaled corticosteroids. So an exciting area in this field while in COPD, the main focus is actually to look for new drugs that target inflammatory pathways which are currently underserved by the typical anti-inflammatory medications in COPD and that may potentially in the future be used both in the chronic maintenance setting but also maybe in the acute setting of an exacerbation; so that is basically our main focus currently.

CV: Thank you, and on a broader scale, what do you feel have been the most important developments in your area over the past year.

KB: Well clearly from my perspective, I think that the most important development in the past year has been the broader introduction of new biologics in the field of severe asthma because I think that these treatments really have changed the lives of many patients that are suitable candidates for treatment with these specific therapies. So that's really an important step forward and as for some of these drugs also the indication has been broadened, for example, to chronic rhinosinusitis for some of these biologics. I think it is ever more important to look at the totality of a patient as not having different paths of diseases or organ manifestations, but really look at the, let's say, holistic approach of treating certain forms of diseases whether they manifest in upper airways or lower airways. So that is really giving us a focus to treat a lot of these patients really in a holistic way. In COPD, I think that the most relevant clinical change has been the introduction of fixed triple therapies into the market. We're now trying to figure out basically in which patients these can make a difference and I think there's been quite some interesting work done in the past year to again refine maybe the role of eosinophils as a biomarker so that was clearly something that kept us intellectually busy over the past year. The second thing is, of course, also relating to biologics in COPD where we have had some more or less disappointing results with some of these treatments which again taught us a lesson that overall drug development is not that easy and it is not easily to be said that you can transfer good experiences with one drug in asthma necessarily to COPD where, as in this particular example, the anti IL-5 molecules have not been that successful as they have been in asthma. But that may again provide us with more information for the future how to better tailor our clinical trials, design clinical trials, and choose the appropriate populations. 
CV: Moving forwards, where do you see development in chronic airway diseases and patient care in 2020 and beyond?

KB: Well I think, first of all, 2020 started not too good for clinical research and drug development in asthma and COPD. We have learned about the big disappointment with one of the CRTH2 antagonists, which has been in the late stages of development for asthma as an add-on therapy, where actually the sponsor developer of the drug has terminated the development program. So that was another lesson to learn that after all things are sometimes not as easy as they were anticipated and I would be interested to see in the next year whether the other types of drugs in this class perform equally-well, lukewarm,-or whether they may be more effective in patients with asthma. Clearly, we will see more data, particularly in asthma, on new biologics, there are data with tezepelumab, for example, the anti-TSLP probably coming up. We will see more data released on the fixed triple combinations in asthma; we have got multiple companies coming up with their data. This is also going to be interesting to see where in the step-up step-down algorithm of asthma treatment these triple combinations will ideally fit in, they're probably going to be a step before biological therapy but the question is a bit whether these triple combinations may also have a potential to be introduced early instead of, for example, increasing the dose of inhaled corticosteroids and/or LABAs. So that is something we are looking forward to and we expect to see some good data and, of course, as the pipeline is still filled also with COPD, at the major conferences we should see some new data on the triple combinations but also new molecules in COPD at ATS latest.

$\mathrm{CV}$ : Interesting, thank you. Beyond your area in pulmonary medicine, what are the most interesting and/or important data you have seen released in the past year and why is that?

KB: Well Chris, I think it's difficult nowadays to respond to a question like that not with an answer that contains the words coronavirus in any way. So this has really been, apart from the social implications and also societal implications and media implications currently, a real big issue. I think that it is also something which is clinically and scientifically and also intellectually very challenging and it's a very interesting area. And we as pulmonologists, of course, as the worst complication of the coronavirus disease is, of course, the pulmonary infection and the related pneumonia, we stand in the forefront of fighting corona. I think that's really an interesting field, particularly for someone who is not so much involved in infectology or virology as I am, so I am learning something new every day, even with my clinical experience and background I am learning something new every day and I am looking forward to the scientific approach to solving that problem. Hopefully, we will see more answers in the next week and hopefully we also will see the spread of the disease slowing down, which would give us more time then to thoroughly address the scientific questions that we need to address to prevent another outbreak like that maybe in the forthcoming seasons.

CV: And finally, what important developments do you predict in pulmonary medicine moving forwards?

KB: Well I think that the field of pulmonary medicine, both in diagnostics and in clinical therapeutic approaches, is getting more and more complex in the future. I think the times where simplicity ruled for a lot of the entities that are comprised in the term of pulmonary medicine, I think these times are over in a certain way. There will be patients still that are easy to treat with a one-size-fits-all approach but I think that the trend clearly is going into the future and it's going to be like that in the near future to talk more about biomarker-targeted therapies as we already see in, for example oncology, where the field is getting more and more complex. But also we are seeing now a strong scientific move ultimately leading to new treatments in the field of interstitial lung diseases where we had a lot of, let's say, information about classifying these diseases or naming these diseases but eventually, the question was always "does it matter because there was no treatment available?" but now we're in an age where, coming back to this better or improved characterization of disease, that we are in an age where we can expect that this ultimately leads to new treatments and that's a trend that I 
would also forecast not only for asthma, COPD, or interstitial lung disease, I think this is a general trend in medicine that there will be a lot to learn beyond the average, let's say, John Doe/ Jane Doe which is nicely and easily treated with cheap and effective drugs but anything beyond that requires definitely some more work of brain and intellectual input which is exciting news and it's, of course, a guarantee that it's going to remain challenging in the next years.

And thank you for those listening to the podcast. We hope you found it interesting and informative. A general journal update is available as part of the original Editorial on our website. The Editorial highlights various key updates such as our recent PubMed indexing and highly read articles in 2019. Do get in touch with the journal if you have any questions at all - contact information is available on the journal's homepage.

\section{Meet the Journal's Editor-in-Chief Professor Rajiv Dhand}

CV: Hello and thank you for listening to the first Pulmonary Therapy podcast, which has been created alongside our 2020 editorial update. My name is Christopher Vautrinot and I am the managing editor of the journal. We thought, considering this is the first podcast, it was an excellent opportunity to introduce the journal's Editors-in-Chief, Dr. Kai-Michael Beeh and Professor Rajiv Dhand. They will discuss their ongoing research focus and comment on the current and future direction of pulmonary medicine.

I'm joined by Professor Rajiv Dhand from the University of Tennessee, Division of Pulmonary Medicine and Section of Critical Care Medicine and the Chairman of the Department of Medicine. Professor Dhand is the US-based Editor-inChief for Pulmonary Therapy and joined the journal in 2019. Professor Dhand is an internationally recognized researcher in the area of aerosolized medicine, particularly with regard to the delivery of medications for COPD.

CV: So Professor Dhand, could you describe in more detail your area expertise and current research focus?
RD: So thanks Chris, I have been involved with inhalation therapy for many years as you have mentioned and particularly the use of inhalation devices in clinical practice. Currently, I'm focusing more on patients with COPD. We have several ongoing studies looking at the use of nebulizers versus inhalers for maintenance treatment in patients with stable COPD as well as bronchodilator therapy in patients with COPD exacerbations who are admitted to the hospital. Recently there has been some interest in determining whether patients with COPD could use dry powder inhalers because they may not be able to generate an adequate peak respiratory flow. I have been collaborating with several investigators to provide some guidance on this issue and have also published a review article in the Journal of Aerosol Medicine and Pulmonary Drug Delivery last year. Another area of research that I'm looking at currently is trying to determine the contamination of nebulizers in patients in the hospital who repeatedly reuse the nebulizer. We are doing a microbiome analysis of these nebulizer units and trying to determine if the contamination of the nebulizer is then transmitted to the patient.

CV: Excellent. And on a broader scale, what do you feel will have been the most important developments in your area over the past year?

RD: One of the most important things I think is the development of smart inhaler technology and adaptive aerosol delivery. So these devices are going to be very helpful in determining whether the patients are using the devices and getting the maximum benefits from the drug by appropriate techniques of use. They can also enhance the amount of drug delivered to the lungs because the drug delivery is synchronized with the patient's breathing. Another area that is coming up that is very important is the lung illness induced by vaping and the study of how vaping influences various anatomical regions in the lungs and how we could perhaps make those compounds have less deleterious effects on the airways and the lung. The third important development has been the use of inhaled antibiotics for non-cystic fibrosis bronchiectasis, especially patients who have infections with Mycobacterium avium 
intracellulare. So several antibiotics have been tried by inhalation including aztreonam, amikacin, and ciprofloxacin, and there have been large-scale randomized clinical trials in patients with non-cystic fibrosis bronchiectasis. Unfortunately, there has not been clear-cut evidence of benefit in preventing exacerbations in these patients with the use of these antibiotic drugs. However, a liposomal formulation of amikacin has been approved for treatment of Mycobacterium avium intracellulare that is not responding to usual oral therapies. Another development that is of potential significance is the use of alpha 1 antitrypsin by aerosolization and other exciting developments are related to the use of vaccines by inhalation to prevent serious infections like measles, and another area that is now being fairly widely used in clinical practice is the use of high-flow nasal cannula to give aerosols to patients who are acutely ill. The predominant feeling had been that in the presence of high flow, the aerosol delivery would be fairly low. However, recent bench studies have shown that given the appropriate techniques of administration can be delivered with a fairly high efficiency in patients who are being treated with high-flow nasal cannula therapy.

$\mathrm{CV}$ : So moving forwards, where do you see developments in aerosolized medicine and patient care this year, 2020, and beyond?

RD: I think this is a particularly exciting time for inhalation therapy because the applications of inhalation therapy are going on expanding. So I see that there will be more emphasis on monitoring of adherence and techniques of use using smart inhalers. I see further developments in the use of inhaled antibiotics for diseases like COPD and bronchiectasis. Also, the increasing role for biologicals for the treatment of asthma and COPD. One of the areas where there is likely to be greater emphasis is the care of patients with COPD exacerbations in the hospital, and after they've been discharged from the hospital there's going to be more emphasis on bronchodilator therapy as well as the types of devices that are prescribed to these patients for inhalation. Another area that seems to be emerging is the use of inhaled drugs for tuberculosis and there are some novel formulations that are being tested for therapy of this widespread illness.

$\mathrm{CV}$ : Thank you, very interesting. Beyond your area in pulmonary medicine, what is the most interesting and/or important data you have seen released in the past year and why is that?

$\mathrm{RD}$ : So there are several areas that have seen remarkable developments. The use of antifibrotic drugs for interstitial lung disease, especially idiopathic pulmonary fibrosis, has brought in a form of treatment for a disease for which we had no therapy in the past and likewise, the use of oral therapies for patients with pulmonary arterial hypertension and lung cancer is offering new modes of treatment to prolong the life of these patients. A landmark development has been the use of triple therapy for patients with cystic fibrosis, which promises to radically change the prognosis for these patients or at least a large majority of these patients with cystic fibrosis. Another area that I think got my attention was the use of robotic bronchoscopy for diagnosis of lung lesions and that is likely to find greater application in the future. There are studies that are ongoing looking at the benefit of this technique. And finally, there's now some hope for treatment of extremely drug-resistant tuberculosis with a new regimen of treatment.

CV: Thank you. And finally, what important developments do you predict in pulmonary medicine moving forwards?

RD: It's always hard to predict what's going to happen in the future but looking at some of the studies that are ongoing. I suspect that we will see approval for inhaled surfactants to treat babies with neonatal respiratory distress syndrome and also for premature babies to actually prevent the occurrence of this entity. The other area that is coming up very significantly is the use of point-of-care ultrasound at the bedside in both pulmonary and critical care medicine. The use of this technology will become fairly routine and it will be an extension of the ability of clinicians to diagnose things at the bedside before, you know, getting formal radiographical or ultrasonographic examinations. I am hopeful that we would have agents to stop or prevent the development of emphysema and that there 
would be something that changes the progressive decline in lung function that one observes in these patients. Another area that is likely to develop more is the use of gene therapies and also CAR T-cell therapy for treating a variety of cancers, including lung cancer. And, finally, I think we may have a breakthrough in a vaccine for tuberculosis.

$\mathrm{CV}$ : Fascinating, well thank you very much for your time Dr. Dhand.

DH: You are welcome.

And thank you for those listening to the podcast. We hope you found it interesting and informative. A general journal update is available as part of the original Editorial on our website. The Editorial highlights various key updates such as our recent PubMed indexing and highly read articles in 2019. Do get in touch with the journal if you have any questions at all-contact information is available on the journal's homepage.

\section{ACKNOWLEDGEMENTS}

Peer review. Please note, contrary to the journal's standard single-blind peer-review process, as an editorial written by the Editor-inChief of the journal this article was not peer reviewed.

Funding. No funding or sponsorship was received for this study or publication of this article.

Authorship. All named authors meet the International Committee of Medical Journal Editors (ICMJE) criteria for authorship for this article, take responsibility for the integrity of the work as a whole, and have given their approval for this version to be published.

Disclosures. Dr. Kai-Michael Beeh received no personal payments from any pharmaceutical entity in the past 5 years. The institution Dr.
Beeh represents has received compensation for services on advisory boards or consulting for Ablynx, Almirall, AstraZeneca, Berlin Chemie, Boehringer, Chiesi, Cytos, Mundipharma, Novartis, Pohl Boskamp, and Zentiva. The institution Dr. Beeh represents has received compensation for speaker activities in scientific meetings supported by Almirall, AstraZeneca, Berlin Chemie, Boehringer, Cytos, ERT, GSK, Novartis, Pfizer, Pohl Boskamp, and Takeda. The institution has further received compensation for design and performance of clinical trials from Almirall, Altana/Nycomed, AstraZeneca, Boehringer, Cytos, GSK, Infinity, Medapharma, MSD, Mundipharma, Novartis, Parexel, Pearl Therapeutics, Pfizer, Teva, Sterna, and Zentiva. Professor Rajiv Dhand has nothing to disclose.

Compliance with Ethics Guidelines. This article is based on previously conducted studies and does not contain any studies with human participants or animals performed by any of the authors.

Data Availability. Data sharing is not applicable to this article as no datasets were generated or analyzed during the current study.

Open Access. This article is distributed under the terms of the Creative Commons Attribution-NonCommercial 4.0 International License (http://creativecommons.org/licenses/ by-nc/4.0/), which permits any non-commercial use, distribution, and reproduction in any medium, provided you give appropriate credit to the original author(s) and the source, provide a link to the Creative Commons license, and indicate if changes were made.

\section{REFERENCE}

1. Beeh K-M. Pulmonary therapy: looking back on 2018 and forward to 2019. Pulm Ther. 2019;5:1-3. https:// doi.org/10.1007/s41030-019-0085-y. 